\title{
Interactive comment on "Area-averaged evapotranspiration over a heterogeneous land surface: Aggregation of multi-point EC flux measurements with high-resolution land-cover map and footprint analysis" by F. Xu et al.
}

\section{Anonymous Referee \#1}

Received and published: 16 December 2016

Accurate estimation of regional evapotranspiration (ET) remains a change in hydrology community. This paper took advantages of the HiWATER experiments to develop an aggregation scheme for accurate estimation of regional ET over an oasis area. In combination with a footprint model and a linear regression, the authors compared the ET aggregated from multi-site eddy covariance measures with that estimated from four large aperture scintillometers. The study addressed an important issue, with qualitycontrolled data obtained from the well-designed experiments. There are several concerns should be clarified before its acceptance for publication. First, in Introduction section the authors argued that existing integration schemes often assume local flux

Printer-friendly version

Discussion paper 
measures are representative of an individual surface cover and thus result in errors. However, the paper did not explicitly address the issue with the data they used. The reviewer would like to see clearly to what extent and under what conditions the assumption may produce the errors. Second, while EC and LAS measures are valuable for large-scale ET estimation, they have measurement errors, either systematic or random. The errors are mixed or propagated into aggregated ET values. Are the measurement errors larger or smaller than the ET differences due to spatial heterogeneity? A careful analysis between EC, LAS and spatial heterogeneity with the matrix flux data would provide valuable insights into the issue which is puzzling for many years. Third, section 4.4 seems not closely relevant to the aggregation topics addressed in the paper. Neither the ET estimates can be validated over the study area as a whole. It is better to remove it from the text.

Specific: Abstract: Page 1 line 20-23: it does not provide any new for audience. 1.Introduction Page 2 line 13: earth -> Earth Page 3 line 2-3: remove one of "remote sensing" Page 3 line 8: there is $->$ there may be Page 4 line 9: a nice statement on representativeness of flux measures over individual surface covers. However, the present version failed to explicitly address the assumption in Results and Discussion. Page 5 line 1-2: "disaggregation approach has not been fully investigated" does not absolutely mean it deserves investigation. Please state it more clearly. 2. Study sites and data Page 6 line 14: two days only? Are they representative or enough to get conclusions that are general? Line 16: Please state the last time the irrigation done. Page 7 line 16: It would be better to use local time. Otherwise, explicitly state the time difference to Beijing time. There are many places throughout the paper with mixture use of "remotely sensed", "remote-sensing", "remote-sensing based", "satellite-based", etc. 3. Methodology Page 9 line 8: add a reference here for footprint model. Page 9 line 11: remove "The". There are many places with misuse of "the" or "a/an" Page 11 line 10: what the mean of "footprint climatology function"? Page 12 line 23: framework -> data processing flow. 4. Results and discussion Page 12 line 17-19: remove the paragraph. It is useless here. Please use $\mathrm{W} / \mathrm{m} 2$ instead of $\mathrm{mm}$ /day throughout the paper. Page 13

Printer-friendly version

Discussion paper 
line 13: how about other periods? Do the differences change with different periods? Page 16 line 16-page 17 line 10: remove the text that describes regional ET over the study area as a whole. It provides no support for the scientific issues addressed.

Interactive comment on Hydrol. Earth Syst. Sci. Discuss., doi:10.5194/hess-2016-602, 2016. 